\title{
Impact of intravenous lidocaine on clinical outcomes of patients with ARDS during COVID-19 pandemia (LidoCovid): A structured summary of a study protocol for a randomised controlled trial
}

Marie Muller ${ }^{1}$, François Lefebvre ${ }^{2}$, Marie-Line Harlay ${ }^{3}$, Ludovic Glady ${ }^{4}$, Guillaume Becker ${ }^{5,6}$, Charlotte Muller ${ }^{7}$, Ouafaa Aberkane ${ }^{8}$, Mira Tawk ${ }^{8}$, Madoé Julians ${ }^{8}$, Arnaud Romoli ${ }^{1}$, Stéphane Hecketsweiler ${ }^{8}$, Francis Schneider ${ }^{3}$, Julien Pottecher ${ }^{1,9}$ and Thiên-Nga Chamaraux-Tran ${ }^{1,10,11,1^{*}}$ (D)

\begin{abstract}
Objectives: The main objective of this study is to evaluate the effect of intravenous lidocaine on gas exchange and inflammation in acute respiratory distress syndrome due or not to Covid-19 pneumonia.

Trial design: This is a prospective monocentric, randomized, quadruple-blinded and placebo-controlled superiority trial. This phase 3 clinical study is based on two parallel groups received either intravenous lidocaine $2 \%$ or intravenous $\mathrm{NaCl}$ 0.9\%.

Participants: This study has been conducted at the University Hospitals of Strasbourg (medical and surgical Intensive Care Units in Hautepierre Hospital) since the 4th November 2020. The participants are 18 years-old and older, hospitalized in ICU for a moderate to severe ARDS according to the Berlin definition; they have to be intubated and sedated for mechanical protective ventilation. All participants are affiliated to the French Social security system and a dosage of beta HCG has to be negative for women of child bearing age .

For the Covid-19 subgroup, the SARS-CoV2 infection is proved by RT-PCR $<7$ days before admission and/or another approved diagnostic technique and/or typical CT appearance pneumonia.

The data are prospectively collected in e-Case Report Forms and extracted from clinical files.

(Continued on next page)
\end{abstract}

\footnotetext{
* Correspondence: thiennga.chamaraux-tran@chru-strasbourg.fr

${ }^{1}$ Hôpital de Hautepierre, Service d'Anesthésie-Réanimation et Médecine

Péri-Opératoire, Hôpitaux Universitaires de Strasbourg, Strasbourg, France

${ }^{10}$ Institut de Génétique et de Biologie Moléculaire et Cellulaire (IGBMC),

Illkirch, France

Full list of author information is available at the end of the article
}

(c) The Author(s). 2021 Open Access This article is licensed under a Creative Commons Attribution 4.0 International License, which permits use, sharing, adaptation, distribution and reproduction in any medium or format, as long as you give appropriate credit to the original author(s) and the source, provide a link to the Creative Commons licence, and indicate if changes were made. The images or other third party material in this article are included in the article's Creative Commons licence, unless indicated otherwise in a credit line to the material. If material is not included in the article's Creative Commons licence and your intended use is not permitted by statutory regulation or exceeds the permitted use, you will need to obtain permission directly from the copyright holder. To view a copy of this licence, visit http://creativecommons.org/licenses/by/4.0/. The Creative Commons Public Domain Dedication waiver (http://creativecommons.org/publicdomain/zero/1.0/) applies to the data made available in this article, unless otherwise stated in a credit line to the data. 
(Continued from previous page)

Intervention and comparator: The participants are randomised in two parallel groups with a 1:1 ratio. In the experimental group, patients receive intravenous lidocaine $2 \%(20 \mathrm{mg} / \mathrm{mL}$ ) (from FRESENIUS KABI France); the infusion protocol provide a bolus of $1 \mathrm{mg} / \mathrm{kg}$ (ideal weight), followed by $3 \mathrm{mg} / \mathrm{kg} / \mathrm{h}$ for the first hour, $1.5 \mathrm{mg} / \mathrm{kg} / \mathrm{h}$ for the second hour, $0.72 \mathrm{mg} / \mathrm{kg} / \mathrm{h}$ for the next 22 hours and then $0.6 \mathrm{mg} / \mathrm{kg} / \mathrm{h}$ for 14 days at most or 24 hours after extubation or ventilator-weaning.

The patients in the control group receive intravenous $\mathrm{NaCl} 0.9 \%(9 \mathrm{mg} / \mathrm{mL}$ ) (from Aguettant, France) as placebo comparator; the infusion protocol provide a bolus of $0.05 \mathrm{~mL} / \mathrm{kg}$ (ideal weight), followed by $0.15 \mathrm{~mL} / \mathrm{kg} / \mathrm{h}$ for the first hour, $0.075 \mathrm{~mL} / \mathrm{kg} / \mathrm{h}$ for the second hour, $0.036 \mathrm{~mL} / \mathrm{kg} / \mathrm{h}$ for the next 22 hours, and the $0.03 \mathrm{~mL} / \mathrm{kg} / \mathrm{h}$ for up to 14 days or 24 hours after extubation or ventilator-weaning. Lidocaine level is assessed at H4, D2, D7 and D14 to prevent local anesthetics systemic toxicity.

Clinical data and biological samples are collected to assess disease progression.

Main outcomes: The primary outcome is the evolution of alveolar-capillary gas exchange measured by the PaO2/ FiO2 ratio after two days of treatment.

The secondary endpoints of the study include the following:

- Evolution of PaO2/FiO2 ratio at admission and after 21 days of treatment

- Number of ventilator-free days

- Anti-inflammatory effects by dosing inflammatory markers at different timepoints (ferritin, bicarbonate, CRP, PCT, LDH, IL-6, Troponin HS, triglycerides, complete blood count, lymphocytes)

- Anti-thrombotic effects by dosing platelets, aPTT, fibrinogen, D-dimers, viscoelastic testing and identification of all thromboembolic events up to 4 weeks.

- Plasmatic concentration of lidocaine and albumin

- Incidence of adverse events like cardiac rhythm disorders, need of vasopressors, any modification of the QRS, QTC or PR intervals every day

- lleus recovery time

- Consumption of hypnotics, opioids, neuromuscular blockers.

- Lengths of stay in the ICU, incidence of reintubation and complications due to intensive care unit care (mortality until 90 days, pneumothorax, bacterial pneumopathy, bronchospasm, cardiogenic shock, acute renal failure, need of renal dialysis, delirium, atrial fibrillation, stroke (CAM-ICU score), tetraplegia (MCR score)).

- Incidence of cough and sore throat at extubation or ventilator-weaning and within 24 hours.

All these outcomes will be evaluated according to positivity to Sars-Cov-2.

Randomisation: The participants who meet the inclusion criteria and have signed written informed consent will be randomly allocated using a computer-generated random number to either intervention group or control group. The distribution ratio of the two groups will be 1:1, with a stratification according to positivity to Sars-Cov-2.

Blinding (masking): All participants, care providers, investigator and outcomes assessor are blinded.

Numbers to be randomised (sample size): We planned to randomize fifty participants in each group, 100 participants total.

Trial Status: The amended protocol version 2.1 was approved by the Ethics Committee "Comité de Protection des Personnes Sud-Méditerranée II on January 8, 2021 and by the Commission Nationale de I'Informatique et des Libertés (CNIL) on November 10, 2020. The study is currently recruiting participants; the recruitment started in November 2020 and the planned recruitment period is three years.

Trial registration: The trial was registered on clinicaltrials.gov on October 30, 2020 and identified by number NCT04609865.

Full protocol: The full protocol is attached as an additional file, accessible from the Trials website (Additional file 1). In the interest in expediting dissemination of this material, the familiar formatting has been eliminated; this Letter serves as a summary of the key elements of the full protocol.

Keywords: COVID-19, Randomised controlled trial, protocol, lidocaine, local anaesthetics, severe acute respiratory syndrome, molecular mechanisms of pharmacological action 


\section{Supplementary Information}

The online version contains supplementary material available at https://doi. org/10.1186/s13063-021-05095-x.

\section{Additional file 1.}

\section{Acknowledgements}

We acknowledge Dr Alain Meyer, Dr Magdalena Szczot, Dr Fanny Planquart, Dr Mathilde Pelloux, Dr Gaëlle Arfeuille, Dr Luc Fenninger, Dr Maleka Schenck Dhif, Dr Jean-Etienne Herbrecht, Dr Thierry Artzner, Dr Max Guillot, Pr Vincent Castelain, for the participation as investigators and their advice for the present protocol, Dr Thomas Lavaux, Dr Dominique Lévêque and Pr Diemunsch for their advice, Sylvie L'Hotellier, Céline Picart and Michel Masuccio for the data collection, the Unité de Coordination de la Biologie des Essais Cliniques (UCBEC) for the biological monitoring and the Centre de Ressources Biologiques / Tumorothèque (CRB) for biological samples storage.

\section{Authors' contributions}

MM: study logistics, medical writing, manuscript preparation; FL: protocol design, study conception, statistical analysis, manuscript preparation; MLH: study conception, study design, study logistics, manuscript preparation; LG: study conception, study design, study logistics, manuscript preparation; GB: study logistics, manuscript preparation; CM: pharmacovigilance, OL: protocol design, study logistics, regulatory affairs; MT: protocol design, study logistics, regulatory affairs, data management, MJ: data management; AR: study conception, study design, study logistics; SH: study conception, study design, study logistics; FS: study conception, study design, study logistics, manuscript preparation, JP: study conception, study design, study logistics, manuscript preparation; TNCT: principal investigator, protocol design, manuscript preparation. The authors read and approved the final manuscript.

\section{Funding}

The study is funded by the Strasbourg University Hospitals (HUS). We declare that the funding organisation has no role in the design of the study, and collection, analysis, interpretation of the data, and writing of the manuscript but all the authors are employees of those hospitals.

\section{Availability of data and materials}

Not applicable.

\section{Ethics approval and consent to participate}

The trial was approved by the Ethics Committee "Comité de Protection des Personnes Sud-Méditerranée II" on June 5, 2020. The amended protocol was approved on January 8, 2021. The first patient was included in the trial on November 12, 2020

In some life-threatening emergency cases, the consent of the patient or the family or even the trusted support person cannot be collected before his inclusion in the study protocol; the CNIL gives a specific agreement for the data processing in these situations (DR-2020-350 dated November 10, 2020). Adults under tutor- or curatorship are not included. But in some emergency cases, this status is only known after the inclusion. If so, the investigator will collect the patient's consent assisted by his guardian or his legal representative.

\section{Consent for publication}

Not applicable.

\section{Competing interests}

The authors declare that they have no competing interests concerning this protocol.

\section{Author details}

${ }^{1}$ Hôpital de Hautepierre, Service d'Anesthésie-Réanimation et Médecine Péri-Opératoire, Hôpitaux Universitaires de Strasbourg, Strasbourg, France. ${ }^{2}$ Hôpital Civil, Service de Santé Publique, GMRC, Hôpitaux Universitaires de Strasbourg, Strasbourg, France. ${ }^{3}$ Hôpital de Hautepierre, Service de Réanimation Médicale, Hôpitaux Universitaires de Strasbourg, Strasbourg, France. ${ }^{4}$ Hôpital de Hautepierre, Laboratoire de Biochimie et Biologie Moléculaire, Hôpitaux Universitaires de Strasbourg, Strasbourg, France.
${ }^{5}$ Hôpital de Hautepierre, Pôle Pharmacie-Pharmacologie, Hôpitaux Universitaires de Strasbourg, Strasbourg, France. ${ }^{6}$ Laboratoire de Pharmacologie et Toxicologie Neurocardiovasculaire UR7296, Département Universitaire de Pharmacologie, Addictologie, Toxicologie et Thérapeutique, Université de Strasbourg, Strasbourg, France. ${ }^{7}$ Vigilance des essais cliniques, Direction de la Recherche Clinique et de I'Innovation, Hôpitaux Universitaires de Strasbourg, Strasbourg, France. ${ }^{8}$ Hôpital Civil, Direction de la Recherche Clinique et de I'Innovation, Hôpitaux Universitaires de Strasbourg, Strasbourg, France. ${ }^{9}$ Faculté de Médecine, Fédération de Médecine Translationnelle de Strasbourg (FMTS), FRU 6702, EA3072, Université de Strasbourg, Strasbourg, France. ${ }^{10}$ Institut de Génétique et de Biologie Moléculaire et Cellulaire (IGBMC), Illkirch, France. ${ }^{11}$ Institut National de la Santé et de la Recherche Médicale (INSERM), Illkirch U 1258, France. ${ }^{12}$ Centre National de la Recherche Scientifique (CNRS), Illkirch UMR 7104, France.

Received: 1 February 2021 Accepted: 2 February 2021

Published online: 11 February 2021

\section{Publisher's Note}

Springer Nature remains neutral with regard to jurisdictional claims in published maps and institutional affiliations.

\section{Ready to submit your research? Choose BMC and benefit from:}

- fast, convenient online submission

- thorough peer review by experienced researchers in your field

- rapid publication on acceptance

- support for research data, including large and complex data types

- gold Open Access which fosters wider collaboration and increased citations

- maximum visibility for your research: over $100 \mathrm{M}$ website views per year

At BMC, research is always in progress.

Learn more biomedcentral.com/submissions 